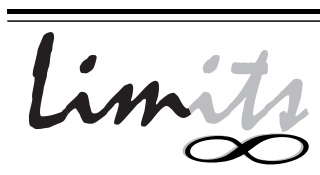

J. Math. and Its Appl.

ISSN : $1829-605 \mathrm{X}$

Vol. 8, No. 2, November 2011, 23-32

\title{
KESTABILAN MODEL MANGSA PEMANGSA DENGAN MANGSA RENTAN DAN TERINFEKSI
}

\author{
Iis Herisman \\ Jurusan Matematika, FMIPA ITS Surabaya \\ iis@matematika.its.ac.id
}

\begin{abstract}
Abstrak
Diberikan model dari suatu epidemik atau kematian atas populasi dari ikan dan pemangsanya. Sistem model akan diuji kestabilan di titik keseimbangannya dengan nilai parameter yang cukup besar. Solusi kestabilan didapat dengan mengambil kondisi awal yang non negatif. Dibentuk model penyakit dan angka kematian dari pemangsa pada waktu bersamaan.
\end{abstract}

Katakunci: Epidemik, Titik keseimbangan, Kestabilan

\section{Pendahuluan}

Suatu model dari [1], menggambarkan tentang lingkungan di laut Salton dengan populasi ikan Tilapia dan Pelikan hampir mengalami kepunahan yang diakibatkan oleh tercemar bakteri Vibrio Vulnificus. Faktor-faktor penyebabnya, diakibatkan lingkungan dengan suhu yang tinggi, tumbuhnya tanaman ganggang secara besarbesaran, keadaan kadar garam yang tinggi, terjadinya polusi dan tingkat oksigen rendah sehingga terjadi penyebaran wabah penyakit tersebut [2]. Model dari [1] berdasarkan asumsi-asumsi didapat: Mangsa terbagi dalam dua kelas, yaitu ikan yang rentan $S(t)$, terinfeksi $I(t)$ yang menular pada waktu $t$.

1. Dalam ketiadaan pemangsa, populasi ikan terinfeksi tumbuh secara logistik. 
2. Ikan yang terinfeksi tidak berreproduksi, diakibatkan masa hidup yang pendek dan tidak dapat sembuh.

3. Infeksi dapat menurunkan daya tahan tubuh ikan, sehingga mudah untuk dimangsa pelikan.

4. Angka kematian pelikan diakibatkan mengkonsumsi ikan adalah relatif konstan.

[3] mengembangkan model tipe II untuk menentukan titik-titik keseimbangan $(s, i, p)$ dengan nilai $s, i, p>0$ pada model Kolmogorov, selanjutnya akan dianalisa pada bidang $(\alpha, e)$. Proses untuk mendapatkan sifat kestabilan diperlukan derivatif parsial pada matriks Jacobian di titik keseimbangan dan metoda Kriteria RouthHurwitz [4].

\section{Metode yang Diterapkan}

\subsection{Model Mangsa dan Pemangsa}

[4] mengasumsikan laju pertumbuhan mangsa dan pemangsa dengan dua model. Asumsi dari model eksponensial: laju pertumbuhan populasi mangsa $=$ angka kelahiran murni mangsa jika dan hanya jika:

$$
\frac{d N(t)}{d t}=r N(t)
$$

Penyelesaian dari (1) didapat:

$$
N(0)=N_{0} e^{r t}
$$

Jika $r>0$ maka untuk $t \rightarrow \sim$ berarti pertambahan populasi mangsa $N(t)$ naik secara eksponensial menuju tak hingga, disebut model kelahiran murni. Jika $r<0$ maka untuk $t \rightarrow \sim$ berarti besarnya pertambahan populasi mangsa $N(t)$ turun secara eksponensial, disebut model kematian yang pada akhirnya mengalami kepunahan. Sedangkan asumsi dari model logistik: laju banyaknya populasi mangsa = angka kelahiran mangsa dikurangi kematian mangsa jika dan hanya jika

$$
\frac{d N(t)}{d t}=r N(t)-\left(1-\frac{N(t)}{K}\right) .
$$

Penyelesaian dari (3) mengasumsikan banyak populasi awal dari mangsa $N(0)=N_{0}$ dan $k_{1}=\frac{N_{0}}{\left(K-N_{0}\right)}$ didapat:

$$
N(t)=\frac{K}{1-n e^{-r t}}
$$

Untuk $t$ menuju tak hingga, banyaknya populasi $N(t)$ tak nol dan mendekati $K$. Konstanta $K$ menunjukan banyak populasi maksimal yang dapat bertahan [5]. 


\subsection{Hasil Eksperimen Holling}

Hasil dari eksperimen Holling:

$$
F(X(t))=a T_{S} X(t)
$$

dengan $X(t)>0, F(X(t))>0$ untuk setiap $t$, masing-masing menyatakan banyaknya disket kertas dan banyaknya disket kertas yang terambil di atas meja pada waktu $t$, dan $\alpha$ laju pencarian dan $T_{S}$ lamanya waktu pencarian. Misalkan $T_{t}$ waktu total yang diberikan dan $b$ rata-rata waktu pengambilan tiap disket kertas, maka didapat: $T_{S}=T_{t}-b F(X(t))$, disubstitusikan ke persamaan (5), didapat:

$$
F(X(t))=\frac{T_{t} a X(t)}{1+a b X(t)}
$$

Jika $X(t)$ diasumsikan terdiri dari disket kertas ukuran kecil dan besar, maka didapat:

$$
F\left(X_{S}(t)\right)=a_{S} T_{s}\left(X_{S}(t)\right) ; F\left(X_{I}(t)\right)=a_{1} T_{S}\left(X_{I}(t)\right)
$$

dengan $F\left(X_{S}(t)\right)>0, X_{S}(t)>0, F\left(X_{I}(t)\right)>0$ dan $X_{I}(t)>0$ untuk setiap $t$. Laju pencarian disket berukuran besar lebih mudah untuk dicapai, berarti $a_{I}>a_{S}$ dengan faktor perbandingannya $v=\frac{a_{I}}{a_{S}}>1$ dan ambil $a=a_{S}$ dan disubstitusikan pada persamaan (7) didapat:

$$
F\left(X_{S}(t)\right)=a T_{S}\left(X_{S}(t)\right) ; F\left(X_{I}(t)\right)=v a T_{S}\left(X_{I}(t)\right)
$$

Jika $b$ rata-rata dari waktu pengambilan disket kertas berukuran kecil dan besar dan $F(X(t))$ jumlah disket berukuran kecil dan besar yang terambil masingmasing $t$ dan $T$ waktu total satuan, didapat:

$$
F\left(X_{S}(t)\right)=b T_{S}\left(X_{S}(t)\right) ; F\left(X_{I}(t)\right)=v a T_{S}\left(X_{I}(t)\right)
$$

dengan $F\left(X_{S}(t)\right)>0, F\left(X_{I}(t)\right)>0$ untuk setiap $t$. Persamaan (9) disubstitusikan ke persamaan (8), didapat:

$$
F\left(X_{S}(t)\right)=\frac{\ell X_{S}(t)}{\gamma+X_{S}(t)+v X_{1}(t)} ; F\left(X_{1}(t)\right)=\frac{v \ell X_{S}(t)}{\gamma+X_{S}(t)+v X_{1}(t)}
$$

Selanjutnya $X_{S}(t)$ dan $X_{I}(t)$ dinyatakan sebagai populasi mangsa, sedangkan $F\left(X_{S}(t)\right)$ dan $F\left(X_{I}(t)\right)$ dinyatakan sebagai populasi mangsa yang berhasil dimangsa [1]. 


\subsection{Analisis Kestabilan Titik Keseimbangan}

Diberikan $\vec{X}=\left(x_{1}, x_{2}, x_{3}\right) \epsilon R^{3}$ dengan $x_{1}, x_{2}, x_{3}>0$, maka $x_{3}>0$ ada jika $\vec{X}=\left(x_{1}, x_{2}\right) \epsilon R^{2}$ dengan $x_{1}, x_{2}>0$ dan perlu untuk mendefinisikan polinomial persamaan karakteristik dari matriks Jacobian [6].

Definisi 2.1 Polinomial karakteristik $\lambda$ derajat $n$ didefinisikan $P_{n}(\lambda)=|A-\lambda I|=$ 0 dengan $\lambda_{i}$ nilai eigen $i=1,2,3, \ldots, n$ dari matriks Jacobian $A_{n \times n}$.

Lemma 2.2 Diberikan Sistem Persamaan Differensial berorder satu

$$
\left\{\begin{array}{l}
\frac{\overrightarrow{d x_{1}}}{d t}=f\left(x_{1}, x_{2}\right) \\
\overrightarrow{\frac{d x_{2}}{d t}}=g\left(x_{1}, x_{2}\right)
\end{array} \quad \text { dengan linierisasi di titik keseimbangan }\left(x_{\sim}, y_{\sim}\right)\right. \text { dikatak- }
$$

an stabil jika dan hanya jika polinomial persamaan karakteristik dari matriks Jacobian $A_{2 \times 2}$ di titik keseimbangan $\left(x_{\sim}, y_{\sim}\right)$ adalah:

$$
|A-\lambda I|=\lambda^{2}+k_{1} \lambda+k_{2}=0
$$

dengan $k_{1}, k_{2}>0$.

Untuk ukuran $A_{3 \times 3}$ di titik $\left(x_{\sim}, y_{\sim}\right)$ adalah:

$$
\lambda^{3}+k_{1} \lambda^{2}+k_{2} \lambda+k_{3}=0
$$

dengan $k_{1}, k_{3}>0$ dan $k_{1} k_{2}>k_{3}$.

Teorema 2.3 Diberikan $\vec{\xi}=\left(\xi_{1}, \xi_{2}, \xi_{3}, \ldots, \xi_{n}\right)$ titik keseimbangan. Jika semua bagian real nilai eigen dari matriks Jacobiannya negatif atau $R_{e}\left(\lambda_{i}\right)<0$ untuk setiap $i$, maka titik keseimbangan dikatakan stabil.

Jadi dari persamaan (11) dan (12), masing-masing didapat 2 dan 3 Kriteria RouthHurwitz. Selanjutnya dari model Kolmogorov akan dicari titik keseimbanagan dan akan diuji kestabilannya.

\section{Pembahasan}

\subsection{Model Epidemik Mangsa dan Pemangsa}

Laju pertumbuhan mangsa dan pemangsa :

$$
\begin{gathered}
\frac{d N(t)}{d t}=r N(t)\left(1-\frac{N(t)}{K}\right)-\frac{m N(t) P(t)}{\gamma+N(t)} \\
\frac{d P(t)}{d t}=\frac{\theta m N(t) P(t)}{\gamma+N(t)}-w P(t)
\end{gathered}
$$


dengan $r$ angka kelahiran perkapita mangsa tanpa ada pemangsa, $w$ angka kematian alami pemangsa, $K$ kapasitas batas, $m$ angka pencarian, $\theta$ faktor konversi dan $\gamma$ koefisien setengah jenuh untuk mangsa dalam satuan waktu [7]. Persamaan (13) dan (14) disebut model tipe II dari Holling.

Berdasarkan pada asumsi (1) model [1] dengan populasi mangsa $S(t)$ dan ikan terinfeksi $I(t)$ dalam satu ekosistem pada waktu $t$. Model tipe II Holling tidak berlaku lagi, karena angka kelahiran perkapita ikan secara logistik dengan populasi $N(t)=S(t)+I(t)$, pengurangan populasi ikan rentan tergantung dan sebanding dengan banyaknya populasi pelikan yang memangsa dengan angka pencarian persatuan waktu, yaitu: $\frac{\ell}{\gamma+S(t)+v I(t)}$ dan pengurangan ikan rentan juga tergantung dan sebanding dengan banyaknya ikan yang rentan dan terinfeksi dengan angka penularan penyakit $\gamma$. Laju pertambahan populasi ikan rentan :

$$
\frac{d S(t)}{d t}=r S(t)\left(1-\frac{S(t) I(t)}{K}\right)-\frac{\ell S(t) P(t)}{\gamma+S(t)+v I(t)}-\lambda S(t) I(t)
$$

Diasumsikan angka pertambahan populasi ikan yang terinfeksi tergantung dan sebanding dengan banyaknya ikan rentan dan terinfeksi dengan angka penularan $\lambda$, pengurangan populasi ikan terinfeksi tergantung dan sebanding dengan populasi pelikan yang memangsa dan angka pencarian persatuan waktu $\frac{\ell}{\gamma+S(t)+v I(t)}$ dan faktor konversi $v$ tidak tergantung pada banyaknya populasi pelikan yang memangsa dengan angka kematian perkapita ikan terinfeksi $\mu$. Misalkan laju pertambahan populasi ikan yang terinfeksi $\frac{d I(t)}{d t}$, didapat:

$$
\frac{d I(t)}{d t}=\lambda S(t) I(t)-\frac{v \ell I(t) P(t)}{\gamma+S(t)+v I(t)}-\mu I(t)
$$

Diasumsikan angka pertambahan populasi pelikan tergantung dan sebanding dengan banyaknya ikan yang rentan dan terinfeksi dengan angka pencarian persatuan waktu $\frac{\ell}{\gamma+S(t)+v I(t)}$ dan faktor konversi $\theta$, pengurangan populasi pelikan tergantung dan sebanding dengan banyaknya ikan yang terinfeksi dan banyaknya populasi pelikan yang memangsa dengan angka pencarian $\frac{\ell}{\gamma+S(t)+v I(t)}$ dan faktor konversi $\psi$ juga tidak tergantung pada populasi ikan dengan angka perkapita alami pelikan $w$. Misalkan laju pertambahan populasi pelikan $\frac{d P(t)}{d t}$, didapat

$$
\frac{d P(t)}{d t}=\frac{\theta \ell(S(t)+v I(t)) P(t)}{\gamma+S(t)+v I(t)}-w P(t)-\frac{\psi v \ell I(t) P(t)}{\gamma+S(t)+v I(t)}
$$

Dengan penskalaan, ambil $P(t)=\frac{r \gamma}{\ell} p(t), \frac{d S(t)}{d t}=\frac{d s(t)}{d t}, d I(t) d t=\frac{d i(t)}{d t}$ dan $\frac{d P(t)}{d t}=\frac{d p(t)}{d t}$ sehingga

$$
\frac{d s(t)}{d t}=s(t)\left\{r\left(\frac{K-s(t)-i(t)}{K}\right) \lambda i(t)-\frac{r \gamma p(t)}{\gamma+s(t)+v i(t)}\right\}
$$


dan substitusikan $\lambda=\frac{r \beta}{K}$ dan $\gamma=K \Gamma$ ke persamaan (18), didapat

$$
\frac{d s(t)}{d t}=s(t)\left\{\frac{r}{K}\left(K-s(t)-i(t)-\beta i(t)-\frac{r K \Gamma p(t)}{K \Gamma+s(t)+v i(t)}\right)\right\}
$$

Karena $r$ dan $K$ masing-masing sebagai angka kelahiran perkapita ikan yang rentan maksimal dan kapasitas batas maksimal, artinya nilai $r$ dan $K$ sama dengan 1, sehingga persamaan (19) menjadi:

$$
\frac{d s(t)}{d t}=s(t)\left\{1-s(t)-(1+\beta) i(t)-\frac{\Gamma p(t)}{\Gamma+s(t)+v i(t)}\right\}
$$

Dengan cara yang sama dari persamaan (16) dan (17),didapat:

$$
\left.\begin{array}{r}
\frac{d i(t)}{d t}=i(t)\left\{\beta(s(t)-\alpha)-\frac{v \Gamma p(t)}{\Gamma+s(t)+v i(t)}\right\} \\
\left.\frac{d p(t)}{d t}=p(t) c\left\{\frac{s}{(} t\right)+v(i(t)-\eta) i(t) \Gamma+s(t)+v i(t)-e\right\}
\end{array}\right\}
$$

Persamaan (20) dan (21) merupakan model epidemik mangsa pemangsa yang berbentuk persamaan differensial berorder satu, diperoleh:

$$
\left\{\begin{aligned}
\frac{d s(t)}{d t} & =s(t) f(s, i, p) \\
\frac{d i(t)}{d t} & =i(t) g(s, i, p) \\
\frac{d p(t)}{d t} & =p(t) h(s, i, p)
\end{aligned}\right.
$$

dengan :

$f(s, i, p)=1-s(t)-(1+\beta) i(t)-\frac{\Gamma p(t)}{\Gamma+s(t)+v i(t)}$

$g(s, i, p)=\beta(s(t)-\alpha)-\frac{v \Gamma p(t)}{\Gamma+s(t)+v i(t)}$

$h(s, i, p)=c\left\{\frac{s(t)+v(i(t)-\eta) i(t)}{\Gamma+s(t)+v i(t)}-e\right\}$

$\beta=\frac{\lambda K}{r} ; \quad c=\theta r \gamma ; \quad \eta=\frac{\psi}{\theta} ; \quad \alpha=\mu \lambda K \operatorname{dan} \Gamma=\gamma K$

Persamaan (22) disebut model bentuk Kolmogorov [8].

\subsection{Titik-titik Keseimbangan}

Titik-titik keseimbangan pada model Kolmogorov yang diberikan terletak pada :

$$
R_{(0,+)}^{3}=\{(s(t), i(t), p(t) / s(t), i(t), p(t)>0)\}
$$

dengan :

$s(t)\left\{1-s(t)-(1+\beta) i(t)-\frac{\Gamma p(t)}{\Gamma+s(t)+v i(t)}\right\}=0 ;$ 


$$
\begin{aligned}
& i(t)\left\{\beta(s(t)-\alpha)-\frac{v \Gamma p(t)}{\Gamma+s(t)+v i(t)}\right\}=0 \text { dan } \\
& p(t) c\left\{\frac{s(t)+v(i(t)-\eta) i(t)}{\Gamma+s(t)+v i(t)}-e\right\}=0
\end{aligned}
$$

dan didapat matriks Jacobian dari fungsi $f, g$ dan $h$ dari parameter $s, i$ dan $p$ adalah

$$
J=\left(\begin{array}{ccc}
f+s f_{s} & s f_{i} & s f_{p} \\
i g_{s} & g+i g_{i} & i g_{p} \\
p h_{s} & p h_{i} & h+p h_{p}
\end{array}\right)=\left(\begin{array}{ccc}
a_{11} & a_{12} & a_{13} \\
a_{21} & a_{22} & a_{23} \\
a_{31} & a_{32} & a_{33}
\end{array}\right)
$$

Parameter $s(t), i(t)$ dan $p(t)$ akan dicari letak titik-titik keseimbangannya, yaitu:

1. Titik keseimbangan $T=(0,0,0)$ tanpa syarat.

2. Titik keseimbangan $S=(1,0,0)$ tanpa syarat.

3. Titik keseimbangan $S I=\left(\alpha, \frac{1-\alpha}{1+\beta}, 0\right)$ dengan syarat $0<\alpha<1$.

4. Titik keseimbangan $S P=\left(\frac{\Gamma e}{1-e}, 0, \frac{1-e(\Gamma+1)}{(1-e)^{2}}\right)$ dengan syarat $e<\frac{1}{\Gamma+1}$.

5. Titik keseimbangan $S I P=(\tilde{s}, \tilde{i}, \tilde{p})$ dengan

$$
\left\{\begin{array}{c}
\left(\begin{array}{cc}
\beta+v & v(1+\beta) \\
(1-e) & v(1-\eta-e)
\end{array}\right)\left(\begin{array}{c}
\tilde{s} \\
\tilde{i}
\end{array}\right)=\left(\begin{array}{c}
v+\beta \alpha \\
\Gamma e
\end{array}\right) \\
\tilde{p}=\frac{\beta(\Gamma+\tilde{s}+v \tilde{i})}{v \Gamma}
\end{array}\right.
$$

Titik-titik keseimbangan akan diselidiki pada sistem koordinat $(\alpha, e)$. Khusus untuk titik $S I P=(\tilde{S}, \tilde{i}, \tilde{p})$ didapat dari teorema dibawah ini.

Teorema 3.1 Titik keseimbangan SIP dikatakan ada jika dan hanya jika $0<$ $\alpha<1 ; e<\frac{1}{\Gamma+1}$ dan $\frac{\alpha(1+\beta)+v(1-\eta)(1-\alpha)}{(\Gamma+\alpha)(1+\beta)+v(1-\alpha)}<e<\frac{v+\beta \alpha}{(v+\beta \alpha)+\Gamma(v+\beta)}$

Letak titik-titik keseimbangan pada bidang $(\alpha, e)$ :

a. Persamaan $\alpha=1$ dan persamaan linier $e_{2}=\frac{v+\beta \alpha}{(v+\beta \alpha)+\Gamma(v+\beta)}$ melalui titik $\left.A=\left(0, \frac{v}{v+\Gamma(v+\beta)}\right) \operatorname{dan} C=\left(1, \frac{1}{\Gamma+1}\right)\right)$. 
b. Persamaan linier $e_{1}=\frac{\alpha(1+\beta)+v(1-\eta)(1-\alpha)}{(\Gamma+\alpha)(1+\beta)+v(1-\alpha)}$ melalui $B=$ $\left(\frac{v(1-\eta)}{\beta+v(1-\eta)-1}, 0\right)$ dan $C=\left(1, \frac{1}{\Gamma+1}\right)$.

Berdasarkan hasil perhitungan sebelumnya didapat:

1. Titik keseimbangan $T$ dan $S$ ada dan tanpa syarat.

2. Titik keseimbangan $S I$ ada, jika $0<\alpha<1$.

3. Titik keseimbangan $S P$ ada, jika $0<e<\frac{1}{\Gamma+1}$.

4. Titik keseimbangan SIP ada, jika $0<\alpha<1 ; e<\frac{1}{\Gamma+1}$ dan $\frac{\alpha(1+\beta)+v(1-\eta)(1-\alpha)}{(\Gamma+\alpha)(1+\beta)+v(1-\alpha)}<e<\frac{v+\beta \alpha}{(v+\beta \alpha)+\Gamma(v+\beta)}$

Hasil perhitungan digambarkan pada bidang $\alpha, e$.

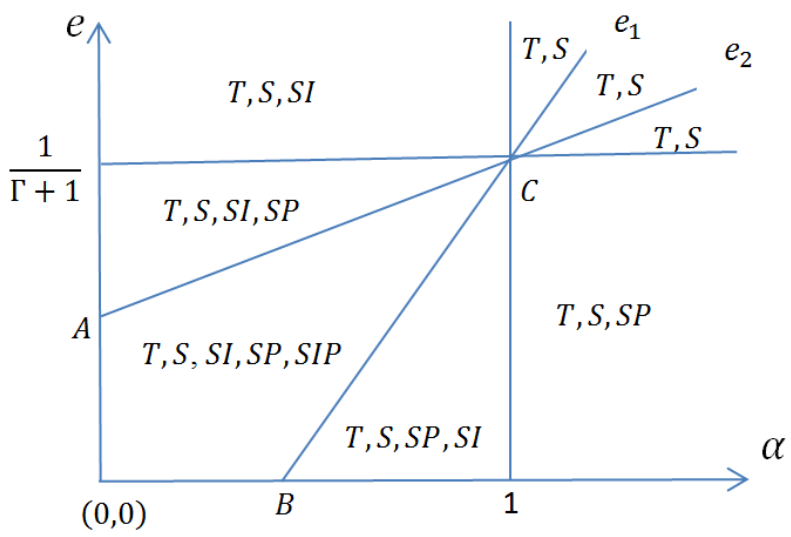

Gambar 1: Letak Titik-titik Keseimbangan Pada Bidang $(\alpha, e)$

Untuk selanjutnya titik-titik keseimbangan pada bidang $(\alpha, e)$ akan diuji kestabilannya.

\subsection{Stabilitas Titik Keseimbangan}

Titik keseimbangan, diuji pada teorema berikut.

Teorema 3.2 Jika $\alpha>1$ dan e $>\frac{1}{\Gamma+1}$, maka titik keseimbangan $S=(1,0,0)$ stabil. 
Untuk titik keseimbangan $S I=\left(\alpha, \frac{1-\alpha}{1+\beta}\right)$, akan diuji dengan teorema berikut.

Teorema 3.3 Jika $e>\frac{\alpha(1+\beta)+v(1-\eta)(1-\alpha)}{(\Gamma+\alpha)(1+\beta)+v(1-\alpha)}$, maka titik keseimbangan $S I=\left(\alpha, \frac{1-\alpha}{1+\beta}, 0\right)$ stabil.

Bukti Dengan menggunakan persamaan (24) didapat matriks Jacobian $J(S I)$

$$
\left(\begin{array}{ccc}
-\alpha & -\alpha(1+\beta) & \frac{-\alpha \Gamma}{\Gamma+\alpha+v \frac{1-\alpha}{1+\beta}} \\
\frac{(1-\alpha) \beta}{1+\beta} & 0 & \frac{1-\alpha}{1+\beta}\left(-\frac{v \Gamma}{\Gamma+\alpha+v \frac{1-\alpha}{1+\beta}}\right) \\
0 & 0 & c\left(\frac{(1+\beta)(\alpha-e \Gamma-e \alpha)+v(1-\alpha)(1-\eta-e}{(\Gamma+\alpha)(1+\beta)+v(1-\alpha)}\right)
\end{array}\right)
$$

dan persamaan karakteristiknya, $|J(S I)-\lambda I|=0$. Selanjutnya dengan ekspansi menurut baris ketiga didapat $\left(c\left(e_{1}-e-\lambda\right)\right)\left(\lambda^{2}+\alpha \lambda+\beta\left(\alpha-\alpha^{2}\right)\right)=0$. Jadi nilai-nilai eigennya $\lambda_{1}=e_{1}-e, \lambda_{2}=\frac{-\alpha+\sqrt{\alpha^{2}-4\left(\alpha-\alpha^{2}\right) \beta}}{2}$ dan $\lambda_{3}=$ $\frac{-\alpha-\sqrt{\alpha^{2}-4\left(\alpha-\alpha^{2}\right) \beta}}{2}$.

Diketahui $e>e_{1}$ dan $\alpha<1$ maka $\lambda_{1}=e_{1}-e<0, \lambda_{2}<0$ dan $\lambda_{3}<0$, akibatnya $R_{e}\left(\lambda_{1}\right)<0, R_{e}\left(\lambda_{2}\right)<0$ dan $R_{e}\left(\lambda_{3}\right)<0$. Menurut teorema 2.3 berarti titik keseimbangan $S I=\left(\alpha, \frac{1-\alpha}{1+\beta}, 0\right)$ stabil.

Titik keseimbangan $S P=\left(\frac{\Gamma e}{1-e}, 0, \frac{1-e(\Gamma+1)}{(1-e)^{2}}\right)$, dengan teorema sebagai berikut.

Teorema 3.4 Jika $\frac{1-\Gamma}{\Gamma+1}<e<\min \left\{\frac{1}{\Gamma+1}, \frac{v+\beta \alpha}{(v+\beta \alpha)+\Gamma(v+\beta)}\right\}$, maka titik keseimbangan $S P=\left(\frac{\Gamma e}{1-e}, 0, \frac{1-e(\Gamma+1)}{(1-e)^{2}}\right)$ stabil.

Teorema berikutnya, ternyata titik SIP, tidak stabil.

Teorema 3.5 Titik keseimbangan SIP $=(\tilde{s}, \tilde{i}, \tilde{p})$ adalah tidak stabil.

Hasil uji kestabilan titik keseimbangan model Kolmogorov adalah semua titik stabil asimtotik kecuali titik SIP, dengan kondisi, menghasilkan proporsi dari ikan yang rentan, ikan yang terinfeksi dan proporsi pelikan tidak menentu pada setiap $t$ atau menjauhi titik keseimbangan SIP. 


\section{Pustaka}

[1] Chattopadhyay,. Bairagi, J. and N, Pelicans at risk in Salton Sea - an eco-epidemiological model, Ecological Modelling, Congressus Numerantium, 136, 103-112, 2001.

[2] Rocke, T,ET AL, Environmental Characteristics Associated with the Occurrence of Avian Botulism in Wetlands of a Northern California Refuge, Journal of Wild-life Management, 63 (1). 358-368, 1999.

[3] Holling, C. S., Some characteristics of Simple Types of Predation and Paratism., Canadian Entomologist, 91, 385-398, 2008.

[4] Arrowsmith, D.K. and Place, C. M., Dynamical System Differential Equations,Maps and Chaotic Behaviour, Chapman and Hall, London, 1992.

[5] Barnes, B., Mathematical Modelling With Case Studies,Bull. Inst. Combin. Appl., 2002.

[6] Kelley, W. and Peterson, A., The Theory of Differential Equations Classical and Qualitative, Upper Saddle River, New Jersey, 2004

[7] Chris, F., Tram, H. and Elizabeth, P, A Predator-Prey Model with Disease Dynamics, Journal of University of Nebraska, Lincoln, 2003.

[8] Lafferty, K.D. AND Morris.,A.K., Altered behavior of parasitized killiincrease susceptibility to predation by bird final hosts. Ecology, 77(5). 1390-1397, 1996. 